An ef fici ent procedure for preparat $i$ on of 2- monoal kyl or

2- monoar yl - 3- et hoxycycl obut anones

\begin{tabular}{|l|l|}
\hline 著者 & $\begin{array}{l}\text { Nat suo Jun- } \mathrm{i} \text { chi, Okuno Ryosuke, Takeuchi } \\
\text { Kosuke, Kawano M zuki, I shi bashi H royuki }\end{array}$ \\
\hline $\begin{array}{l}\text { j our nal or } \\
\text { publ i cat i on t i t l e }\end{array}$ & Tetrahedr on Let ter s \\
\hline vol une & 51 \\
\hline number & 29 \\
\hline page r ange & $3736-3737$ \\
\hline year & $2010-07-21$ \\
\hline URL & ht t p: //hdl . handl e. net /2297/24795 \\
\hline
\end{tabular}




\section{Graphical Abstract}

To create your abstract, type over the instructions in the template box below.

Fonts or abstract dimensions should not be changed or altered.

\begin{tabular}{|c|c|c|c|c|c|}
\hline An efficient procedure for prepara & of 2 & Leave $t$ & ea blank for abstra & info. & \\
\hline $\begin{array}{l}\text { ethoxycyclobutanones } \\
\text { Jun-ichi Matsuo,* Ryosuke Okuno, } \\
\text { Kosuke Takeuchi, Mizuki Kawano and } \\
\text { Hiroyuki Ishibashi }\end{array}$ & & & $\begin{array}{l}i-\mathrm{Pr}_{2} \mathrm{NEt} \\
\text { or } \\
2,6 \text {-lutidine }\end{array}$ & & R \\
\hline $\begin{array}{l}\text { School of Pharmaceutical Sciences, } \\
\text { Institute of Medical, Pharmaceutical and } \\
\text { Health Sciences, Kanazawa University, } \\
\text { Kakuma-machi, Kanazawa 920-1192, } \\
\text { Japan }\end{array}$ & & & $\begin{array}{l}\text { sealed tube } \\
90^{\circ} \mathrm{C}, 2 \mathrm{~h}\end{array}$ & $\mathrm{R}=$ & $\begin{array}{l}\text { OEt } \\
\text { l, Ar }\end{array}$ \\
\hline
\end{tabular}




\title{
An efficient procedure for preparation of 2-monoalkyl or 2- monoaryl-3-ethoxycyclobutanones
}

\author{
Jun-ichi Matsuo,* Ryosuke Okuno, Kosuke Takeuchi, Mizuki Kawano and Hiroyuki Ishibashi \\ School of Pharmaceutical Sciences, Institute of Medical, Pharmaceutical and Health Sciences, Kanazawa University, Kakuma-machi, \\ Kanazawa 920-1192, Japan
}

\begin{abstract}
Optimized reaction conditions for preparation of various 2-monosubstituted 3-ethoxycyclobutanones are described. 2Monoalkyl 3-ethoxycyclobutanones were efficiently prepared by the reaction of the corresponding carboxylic acid chlorides and an excess amount of ethyl vinyl ether in the presence of diisopropylethylamine at $90{ }^{\circ} \mathrm{C}$ in a sealed tube. 2-Monoaryl 3-ethoxycyclobutanones were prepared by using 2,6-lutidine as a base in the above mentioned procedure. (c) 2010 Elsevier Science. All rights reserved
\end{abstract}

Cyclobutanones are important and versatile compounds in organic synthesis. ${ }^{1} \quad$ Among them, 3-ethoxycyclobutanones have been employed for preparation of bicyclobutanes ${ }^{2}$ and silyloxy dienes. ${ }^{3}$ We recently found new synthetic utility of 3-ethoxycyclobutanones as a useful building block for synthesis of various types of six-membered cyclic compounds. Thus, Lewis acid activates 2,2-disubstituted 3ethoxycyclobutanones by cleaving the more substituted C2$\mathrm{C} 3$ bond of the cyclobutanone ring to form a zwitterionic intermediate, which reacts with carbonyl compounds, ${ }^{4}$ allylsilanes, $^{5}$ or silyl enol ethers ${ }^{6}$ to afford the corresponding cyclic compounds. In our investigation of these reactions, we encountered difficulty in preparation of 2-monosubstituted or non-substituted 3ethoxycyclobutanones. That is, 3-ethoxy-2monoalkylcyclobutanones were synthesized in low yields (vide infra) by the conventional procedure of employing the corresponding carboxylic acid chloride, triethylamine, and ethyl vinyl ether (EVE) in refluxing acetonitrile. ${ }^{7}$ We report here a widely applicable procedure for preparation of 2-monosubstituted 3-ethoxycyclobutanones.

The conventional conditions for synthesis of 3ethoxycyclobutanones by [2 + 2] cycloaddition of ethyl vinyl ether (EVE) and ketene, which was generated in situ from carboxylic acid chloride $\mathbf{1}$ with triethylamine in refluxing acetonitrile, gave the desired 2-benzyl-3ethoxycyclobutanone 2 in 7\% yield (Table 1, Entry 1). [2 + 2] Cycloaddition using an excess amount (10 equivalents) of EVE without acetonitrile in a sealed tube gave 2 in a slightly improved yield (12\% yield, Entry 2). It was thought that an undesired side reaction such as dimerization of ketene via species $\mathbf{4}$, which was formed by the addition of triethylamine hydrochloride to reactive monoalkyl ketene $3,^{7 a, 8}$ was the reason for low yields of cyclobutanone
Table 1. Optimization of Reaction Conditions

\begin{tabular}{|c|c|c|c|c|}
\hline & $\mathrm{Cl}^{+}=$ & $\begin{array}{c}\text { base } \\
\underset{90{ }^{\circ} \mathrm{C}, 2 \mathrm{~h}}{(1.2 \text { equiv) }} \\
\text { sealed tube }\end{array}$ & cis-2 & $\square_{\text {trans-2 }}$ \\
\hline Entry & Base & EVE (equiv) & Yield (\%) & cis/trans ${ }^{b}$ \\
\hline $1^{\mathrm{c}}$ & $\mathrm{Et}_{3} \mathrm{~N}$ & 2 & 7 & $10: 90$ \\
\hline 2 & $\mathrm{Et}_{3} \mathrm{~N}$ & 10 & 12 & $17: 83$ \\
\hline 3 & $i-\mathrm{Pr}_{2} \mathrm{NEt}$ & 10 & 80 & $62: 38$ \\
\hline 4 & $\mathrm{Bu}_{3} \mathrm{~N}$ & 10 & 31 & $10: 90$ \\
\hline 5 & $i-\mathrm{Bu}_{3} \mathrm{~N}$ & 10 & trace & - \\
\hline 6 & 2,6-lutidine & 10 & $36^{\mathrm{b}}$ & $61: 39$ \\
\hline 7 & $i-\mathrm{Pr}_{2} \mathrm{NEt}$ & 5 & 54 & 61:39 \\
\hline
\end{tabular}

${ }^{a}$ Isolated yield unless otherwise mentioned.

${ }^{\mathrm{b}}$ Determined by ${ }^{1} \mathrm{H}$ NMR.

c The reaction was performed by using acetonitrile as a solvent at reflux under $\mathrm{N}_{2}$.

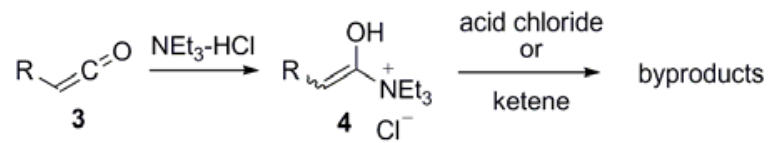

Scheme 1. Undesired formation of reactive intermediate 4

2 (Scheme 1). Therefore, hindered amines were employed in order not to form 4 . It was then found that diisopropylethylamine was a suitable amine for the cycloaddition reaction, and cyclobutanone 2 was obtained 
in $80 \%$ yield (Entry 3). ${ }^{9} \quad$ Tributylamine, triisobutylamine, and 2,6-lutidine were not effective (Entries 4-6). Decreasing the amount of EVE from 10 to 5 equivalents resulted in decrease in the yield of 2 to 54\% (Entry 7). The use of inorganic bases such as $\mathrm{K}_{2} \mathrm{CO}_{3}$ and $\mathrm{Cs}_{2} \mathrm{CO}_{3}$ in the presence of a catalytic amount of diisopropylethylamine was not effective. Raising the reaction temperature from $90{ }^{\circ} \mathrm{C}$ to $120^{\circ} \mathrm{C}$ did not improve the yield of cyclobutanone 2 , and the reaction at $60^{\circ} \mathrm{C}$ gave 2 in a trace amount.

Table 2. Synthesis of various 2-monoalkyl 3-ethoxycyclobutanones 7a-i

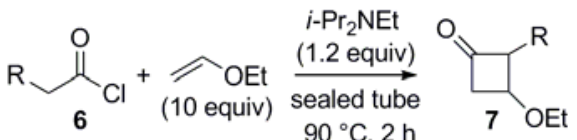

\begin{tabular}{ccccc}
\hline Entry & $\mathrm{R}$ & $\mathbf{7}$ & ${\text { Yield }(\%)^{\mathrm{a}}}^{\text {cis/trans }}$ & cr $^{\mathrm{b}}$ \\
\hline 1 & $\mathrm{H}$ & $\mathbf{7 a}$ & 37 & - \\
2 & $\mathrm{Me}$ & $\mathbf{7 b}$ & 77 & $53: 47$ \\
3 & $\mathrm{Et}$ & $\mathbf{7 c}$ & 78 & $16: 84$ \\
4 & $\mathrm{Pr}$ & $\mathbf{7 d}$ & 71 & $27: 73$ \\
5 & $\mathrm{Bu}$ & $\mathbf{7 e}$ & 76 & $30: 70$ \\
6 & $\mathrm{Hex}$ & $\mathbf{7 f}$ & 77 & $58: 42$ \\
7 & $i-\mathrm{Bu}$ & $\mathbf{7 g}$ & 77 & $24: 76$ \\
8 & $i-\mathrm{Pr}$ & $\mathbf{7 h}$ & 50 & $31: 69$ \\
9 & $t-\mathrm{Bu}$ & $\mathbf{7 i}$ & 48 & $36: 64$ \\
& & & $(74)^{\mathrm{c}}$ & $(54: 46)^{\mathrm{c}}$
\end{tabular}

\footnotetext{
${ }^{\mathrm{a}}$ Isolated yield.

${ }^{\mathrm{b}}$ Determined by ${ }^{1} \mathrm{H}$ NMR.

${ }^{c}$ Triethylamine was used instead of diisopropylethylamine.
}

Next, several 2-alkyl-3-ethoxycyclobutanones 7 were prepared by using the corresponding carboxylic acid chloride 6, diisopropylethylamine and 10 equivalents of EVE in a sealed tube at $90{ }^{\circ} \mathrm{C}$ (Table 2). It should be noted that 2-nonsubstituted 3-ethoxycyclobutanone 7a, which was not obtained by the conventional method of using triethylamine as a base, was obtained in 37\% yield (Entry $1)^{10}$ This is a convenient method for preparation of $7 \mathbf{a}$ because a special apparatus (ketene lamp) is not required in the present method. Linear nonbranched ketenes such as methyl ketene, ethyl ketene, propyl ketene, and butyl ketene, which were reported to dimerize easily, ${ }^{7 \mathrm{a}}$ reacted with EVE smoothly to afford the corresponding cyclobutanones in good yields (Entries 2-6). Ketenes bearing a $\beta$-blanched alkyl group generated from acid chloride $\mathbf{6 g}$ gave the corresponding cyclobutanone $\mathbf{7 g}$ in $77 \%$ yield, whereas $\alpha$-branched ketenes generated from acid chlorides $\mathbf{6 h}$ and $\mathbf{6 i}$ gave the corresponding cyclobutanones $\mathbf{7 h}$ and $\mathbf{7 i}$ in $48-50 \%$ yields (Entries 7-9). In the reaction of $\mathbf{6 i}$, triethylamine was found to be more suitable than diisopropylethylamine probably because smooth abstraction of the $\alpha$-proton of $\mathbf{6 i}$ with triethylamine took place, and formation of undesired $\mathbf{4}$ from tert-butyl ketene was difficult due to its steric hindrance.
Table 3. Synthesis of various 2-monoaryl 3-ethoxycyclobutanones 9a-i

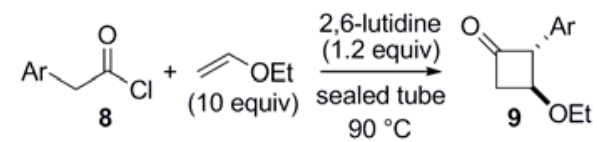

\begin{tabular}{|c|c|c|c|c|}
\hline Entry & $\mathrm{Ar}$ & 9 & Yield (\%) $^{\mathrm{a}}$ & cis/trans ${ }^{b}$ \\
\hline 1 & $\mathrm{Ph}$ & 9a & 75 (trace) $^{c}$ & 11:89 \\
\hline 2 & $p-\mathrm{MeOC}_{6} \mathrm{H}_{4}$ & $9 b$ & 74 & $14: 86$ \\
\hline 3 & $p-\mathrm{MeC}_{6} \mathrm{H}_{4}$ & 9c & 56 & 11:89 \\
\hline 4 & $o-\mathrm{MeC}_{6} \mathrm{H}_{4}$ & 9d & 74 & $6: 94$ \\
\hline 5 & $p-\mathrm{ClC}_{6} \mathrm{H}_{4}$ & $9 e$ & 56 & $12: 88$ \\
\hline 6 & 1-Naph & 9f & 83 & 7:93 \\
\hline 7 & 2-Naph & $9 g$ & 64 & $6: 94$ \\
\hline 8 & 2-Thienyl & $9 h$ & 62 & 7:93 \\
\hline 9 & 3-Thienyl & $9 i$ & 70 & 7:93 \\
\hline
\end{tabular}

${ }^{\mathrm{a}}$ Isolated yield.

${ }^{\mathrm{b}}$ Determined by ${ }^{1} \mathrm{H}$ NMR.

${ }^{\mathrm{c}}$ Diisopropylethylamine was used instead of 2,6-lutidine.

Preparation of 2-aryl-3-ethoxycyclobutanones 9 from the corresponding $\alpha$-aryl carboxylic acid chlorides $\mathbf{8}$ is shown in Table 3. The use of diisopropylethylamine gave the desired cyclobutanone $\mathbf{9 a}$ in a trace amount, whereas the use of 2,6-lutidine gave 9a in 75\% yield (Entry 1). It was assumed that diisopropylethylamine-mediated formation of phenyl ketene took place too rapidly before cycloaddition with EVE because of increased acidity of the $\alpha$-proton of carboxylic acid chloride 8a. Other $\alpha$-aryl carboxylic acid chlorides $\mathbf{8 b}-\mathbf{i}$ also reacted with EVE smoothly in the presence of 2,6-lutidine (Entries 2-9).

In summary, we have developed a convenient method for synthesis of 2-monoalkyl or 2-monoaryl 3ethoxycyclobutanones by using the corresponding carboxylic acid chlorides and EVE in the presence of sterically hindered amines such as diisopropylethylamine or 2,6-lutidine. ${ }^{11}$ Two points are thought to be important for the efficient synthesis of 2-monosubsituted 3ethoxycyclobutanones from carboxylic acid chloride and EVE. One is smooth generation of ketene at $90{ }^{\circ} \mathrm{C}$, a temperature at which ketene can react readily with EVE. The other is to avoid a reaction between ketene and amine hydrochloride to form intermediate 4 .

\section{Acknowledgments}

This work was partially supported by a Grant-in-Aid for Scientific Research from the Ministry of Education, Culture, Sports, Science, and Technology, Japan. 


\section{References}

1. (a) Lee-Ruff, E.; Mladenova, G. Chem. Rev. 2003, 103, 1449-1483; (b) Namyslo, J. C.; Kaufmann, D. E. Chem. Rev. 2003, 103, 1485-1537; (c) Belluš, D.; Ernst, B. Angew. Chem., Int. Ed. Engl. 1988, 27, 797-827.

2. Sieja, J. B. J. Am. Chem. Soc. 1971, 93, 130-136.

3. Aben, R. W.; Scheeren, H. W. J. Chem. Soc., Perkin Trans. 1 1979, 3132-3138.

4. Matsuo, J.; Sasaki, S.; Tanaka, H.; Ishibashi, H. J. Am. Chem. Soc. 2008, 130, 11600-11601.

5. Matsuo, J.; Sasaki, S.; Hoshikawa, T.; Ishibashi, H. Org. Lett. 2009, 11, 3822-3825.

6. Matsuo, J.; Negishi, S.; Ishibashi, H. Tetrahedron Lett. 2009, 50, 5831-5833.

7. (a) Hyatt, J. A.; Raynolds, P. W. Org. React. 1994, 45, 159-646; (b) Ward, R. S. The Chemistry of Ketenes, Allenes and Related Compounds 1980, 1, 223-277.

8. Farnum, D. G.; Johnson, J. R.; Hess, R. E.; Marshall, T. B.; Webster, B. J. Am. Chem. Soc. 1965, 87, 51915197.

9. Typical Procedure (Table 1, Entry 3): to a solution of diisopropylethylamine $(0.28 \mathrm{~mL}, 1.64 \mathrm{mmol})$ and ethyl vinyl ether (1.28 mL, $13.4 \mathrm{mmol}$ ) was added 3-phenylpropionyl chloride $1(0.20 \mathrm{~mL}, 1.35 \mathrm{mmol})$ in a sealed tube. The reaction mixture was heated with stirring at $90{ }^{\circ} \mathrm{C}$ (bath temperature) for $2 \mathrm{~h}$. After cooling to room temperature, the reaction was quenched with saturated aqueous sodium hydrogencarbonate solution, and the mixture was extracted with ethyl acetate. The combined organic extracts were washed with brine, dried over anhydrous sodium sulfate, filtered, and concentrated. The crude product was purified by column chromatography on silica gel (hexane/ethyl acetate =
30:1 to 8:1) to afford 2-benzyl-3-ethoxycyclobutanone 2 (220 mg, 80\%). Characterization data and NMR spectra are shown in the Supplemenrary Data.

10. Preparation of $7 a$ (10 times scale, Table 2, Entry 1): to a solution of diisopropylethylamine $(2.8 \mathrm{~mL}, 16.4 \mathrm{mmol})$ and ethyl vinyl ether $(13.0 \mathrm{~mL}, 136 \mathrm{mmol})$ was added acethyl chloride $(0.96 \mathrm{~mL}, 13.5 \mathrm{mmol})$ in a sealed tube. The reaction mixture was heated with stirring at $90{ }^{\circ} \mathrm{C}$ (bath temperature) for $2 \mathrm{~h}$. After cooling to room temperature, the reaction was quenched with saturated aqueous sodium hydrogencarbonate solution, and the mixture was extracted with ether. The combined organic extracts were washed with brine, dried over anhydrous sodium sulfate, filtered, and concentrated. The crude product was purified by column chromatography on silica gel (pentane/ether = 8:1) to afford 3ethoxycyclobutanone 7a (572 mg, 37\%).

11. The present method was not suitable for preparation of 2,2dialkyl 3-ethoxycyclobutanones. The reaction between isobutyryl chloride and EVE with diisopropylethylamine or triethylamine under the present reaction conditions gave 2,2dimethyl-3-ethoxycyclobutaone in $8 \%$ or $46 \%$ yield, respectively.

\section{Supplementary Data}

Supplementary data including full characterization of all new cyclobutanones $(2,7 \mathbf{7}-\mathbf{i}$, and $9 \mathbf{9 a - i})$ and their ${ }^{1} \mathrm{H}$ and ${ }^{13} \mathrm{C}$ NMR spectra are available in online version. 